\title{
"IDIAY, ¿QUÉ DIGO?" \\ ALGUNAS CONSIDERACIONES SOBRE LOS MENSAJES DEJADOS EN LAS MÁQUINAS CONTESTADORAS
}

\author{
Carlos Sánchez Avendaño
}

\begin{abstract}
RESUMEN
Este artículo analiza la especificidad, las características estructurales y el manejo de las estrategias de cortesía en los mensajes dejados en las máquinas contestadoras de una casa de habitación y de un teléfono celular.
\end{abstract}

\section{ABSTRACT}

This article analyses the specificity, structural features and use of politeness strategies in messages left in answering machines of a home and a cellular phone.

\section{Introducción}

"Dos-siete-nueve-siete-cero-siete-uno no se encuentra disponible en este momento. Por favor, deje un mensaje después del tono. Cuando haya terminado de grabar, puede colgar o marcar uno para más opciones"

Las palabras anteriores no resultan nada extrañas en la actualidad. De hecho, con la popularización de los teléfonos celulares, además de la introducción por parte del ICE del servicio de mensajería, el texto en cuestión se ha convertido en una emisión casi cotidiana a la que una buena parte de la población se ha acostumbrado. ¿A qué responde la forma estándar del mensaje citado? ¿Qué tipo de secuencias lingüísticas se esperaría que, a continuación, emitiera la persona que llamó? ¿De cuáles recursos se valdrá para llevar a buen término la acción comunicativa que le propone el mensaje, a pesar de que lo que en realidad pretendía era entablar una conversación telefónica?

Partiendo de la necesidad de abordar nuevos aspectos de la competencia discursiva de los hablantes, este artículo trata de un tipo específico de discurso: los mensajes en la máquina contestadora desde distintos ángulos: su carácter oral atípico, su estructura de marco y las estrategias de cortesía que se ponen en práctica a la hora de llevar a cabo su emisión. Los tres apartados, entonces, intentan dar respuesta a las interrogantes planteadas. 


\subsection{El corpus}

El corpus analizado consiste en catorce mensajes telefónicos grabados en una máquina contestadora automática de una casa de habitación, seis dejados en la contestadora de un teléfono celular y dos conversaciones telefónicas; estas últimas sirvieron de parámetro comparativo. Dado que el corpus es relativamente pequeño, no es el interés de este trabajo proponer generalidades universales, sino solamente analizar los datos recogidos como muestras de una práctica discursiva relativamente nueva en nuestro medio. Todos los nombres de los involucrados han sido cambiados; los números de teléfono se han sustituido por la marca XXXX, y algunos datos se han omitido por resultar irrelevantes para el análisis o por razones de confidencialidad.

\section{El carácter oral atípico de los mensajes dejados en la contestadora}

Los mensajes telefónicos más tradicionales consisten en la anotación por escrito de algunos datos considerados relevantes. En estas situaciones, normalmente la persona que contesta el teléfono no es el interlocutor buscado por el que marca el número; por consiguiente, después de la casi rigurosa pregunta “¿desea dejar algún recado?”, el que llama deja ciertos datos personales y, en determinadas ocasiones y dependiendo del tema, explica la razón de su llamada. La persona que contesta debe anotar los datos y resumir el "asunto", para lo cual cuenta muchas veces con un documento preestablecido, que regularmente incluirá las siguientes secciones: 'Para', 'De parte de', 'Teléfono' y 'Motivo'.

Esta situación en la que se escribe parte de la información obtenida por medio de una transacción comunicativa oral continúa vigente en nuestra cultura, no solo en las oficinas, sino también en las casas de habitación cuando la persona llamada no se encuentra en disposición de atender. Sin embargo, cabe notar, asimismo, que la aparición y extensión del uso de teléfonos celulares, por cuanto normalmente estos son de uso estrictamente personal, ha contribuido con el cambio de esta situación, ya empezado por la instalación de máquinas contestadoras en las casas y por la activación del servicio de mensajería de las compañías telefónicas.

Si ya de por sí los mensajes telefónicos escritos merecen un estudio propio por ser un paso gráfico de la modalidad oral, los mensajes orales llaman la atención sobre su especificidad como discurso oral atípico.

La situación de enunciación oral prototípica se caracteriza por la participación in situ, cara a cara, y simultánea de los interlocutores, quienes, además de compartir tiempo y espacio de enunciación, negocian la transacción comunicativa a partir de sus características psicosociales (jerarquía, imagen, ámbito en el que se realiza la conversación, etc.). El canal empleado en la comunicación es oral-auditivo (al menos para las lenguas orales), pero el desarrollo tecnológico permite en la actualidad el empleo de canales diferidos (radio, televisión, grabaciones de audio y video). La situación enunciativa de la conversación telefónica utiliza un canal directo, aunque despojado de los recursos cinésicos y proxémicos con los que cuenta la comunicación cara a cara.

En cuanto a sus características lingüísticas, parece que la conversación telefónica normal comparte casi los mismos rasgos de la conversación espontánea cara a cara, tal como los 
presentan Casalmiglia y Tusón (1999: 32-3) a partir de la reseña de las investigaciones producidas por los analistas de la conversación:

1. Cambio de hablantes recurrente (diálogo).

2. No intervención de más de una persona a la vez.

3. Solapamientos (intervención de dos o más hablantes al mismo tiempo) comunes pero breves.

4. Transiciones entre un turno de habla y el siguiente sin intervalos ni solapamientos o con un breve intervalo.

5. Orden no fijo de los turnos de palabra.

6. Duración no fija de los turnos de habla.

7. Duración no especificada de la conversación.

8. Tema de la conversación no especificado previamente.

9. Distribución de los turnos de habla no especificada previamente.

10. Discurso continuo o discontinuo.

11. Uso de técnicas (estrategias) para la distribución de los turnos.

12. Utilización de diferentes unidades de construcción de los turnos.

13. Empleo de mecanismos para la reparación de los errores o las transgresiones en la toma de la palabra.

Habría dos aspectos en los que la conversación telefónica diferiría sustancialmente de la conversación espontánea cara a cara: el número de hablantes (en esta última puede variar, pero en la conversación telefónica lo normal es que sean únicamente dos, pues incluso la conversación entre tres sigue siendo bastante rara) y el empleo de recursos no lingüísticos para indicar el cambio de turno, la toma de palabra o la reparación y el reforzamiento de los enunciados verbales (en la conversación cara a cara, como ya se dijo, se emplean estrategias cinésicas y proxémicas al lado de las propiamente lingüísticas y paralingüísticas). El siguiente ejemplo representa una conversación telefónica prototípica ${ }^{1}$ :

\section{$[\ldots]$}

A. ¿Tiene que ir la crítica ahí en el trabajo?

B. Sí

A. O sea / digamos / ¿yo le saco fotocopia al libro?

B. $\quad$ Ajá

A. Y las meto así

B. Sí

A. Ah bueno / ¿qué está escribiendo?

B. ¿Qué? ¿¿qué? / ¡cómo le saco fotocopia al libro?

A. A la crítica / yo hago el resumen de los puntos en común

B. $\quad$ Sí / sí pero no no / ah bueno sí sí

A. $\quad$ Pero pongo ahí las críticas

B. No no / ¿para qué?

A. ¿No es necesario?

B. Na no

A. Ah bueno bueno bueno / después me me dijo / bueno cuando ya tenga el material y todo / bueno / a ella se le puede ir preguntando // el jueves

B. $\quad$ Ajá 


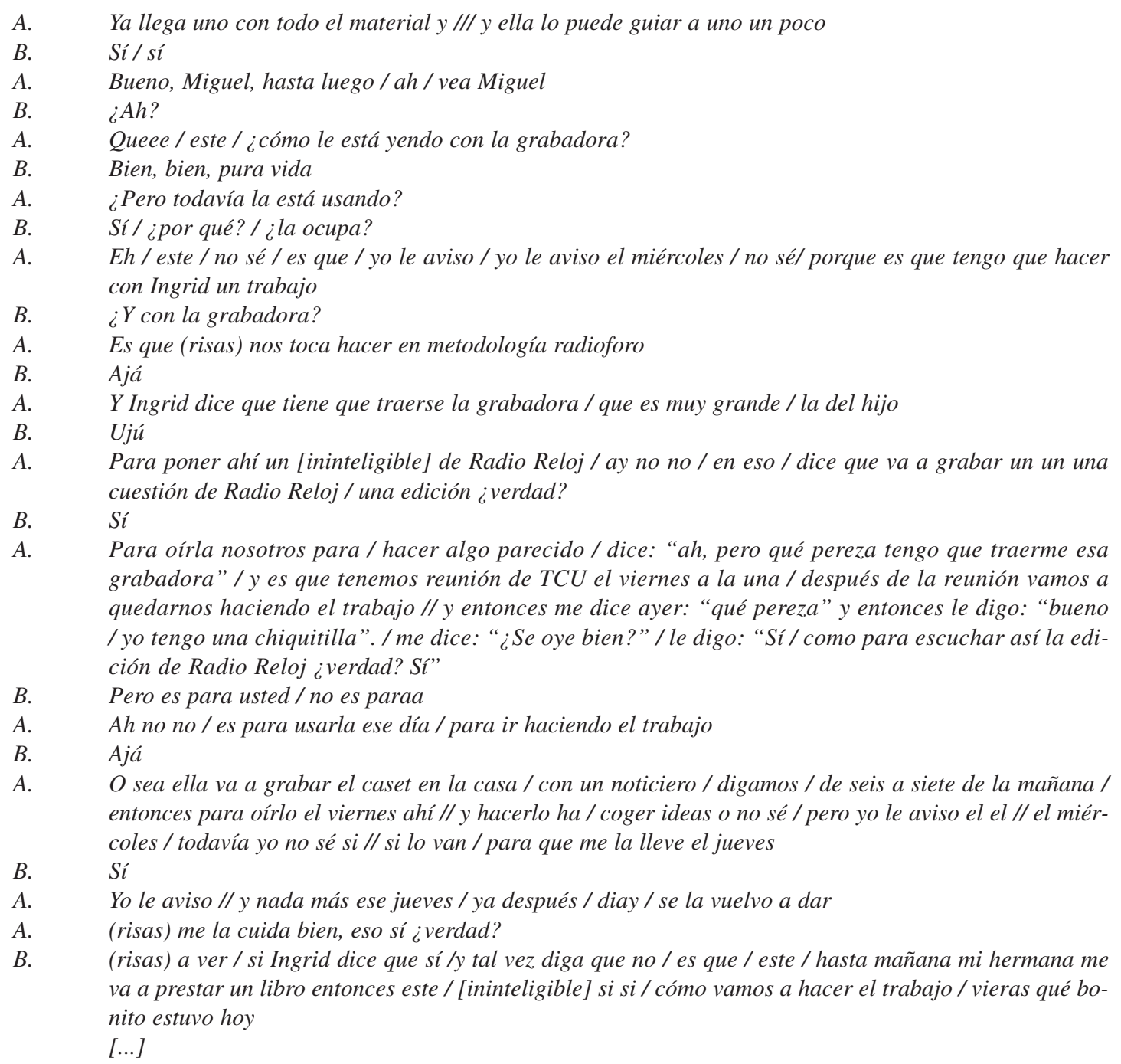

Al observar el fragmento transcrito, se nota cómo se cumplen las propiedades señaladas para la conversación espontánea: los cambios de turnos son recurrentes y, en las secciones monologadas más extensas, el oyente muestra su participación por medio de indicadores especiales (ajá, ujú, sí), el tema se va negociando conforme avanza el evento comunicativo (un trabajo académico, la grabadora prestada, el proyecto para un curso) y los hablantes rectifican la información a lo largo de sus turnos de habla (véase cómo B cambia sus respuestas iniciales y cómo A le pide la devolución de la grabadora poco a poco y tratando de no exigir ni imponérsele a B, para lo cual mide constantemente su reacción). Del mismo modo, se nota cómo la conversación telefónica comparte con la conversación cara a cara la caracterización que de ella formulan Calsamiglia y Tusón (1999: 33): "las conversaciones espontáneas suelen tener un alto grado de indefinición, de imprevisibilidad y, como consecuencia, de improvisación por parte de quienes intervienen en ella". 
En las conversaciones espontáneas, los turnos para tomar la palabra se organizan, generalmente, por medio de pares adyacentes. En este sentido, las conversaciones telefónicas no parecen ser una excepción.

De acuerdo con Emanuel Schegloff (1986), la conversación por teléfono tiene una estructura definida prototípica, en la que el tipo de acto de habla que caracteriza la apertura de la interacción conversacional es el de la secuencia "convocatoria-respuesta". La secuencia conversacional puede ser descrita con la fórmula $a b a b a b$, donde $a$ y $b$ son las partes de la conversación Esta estructura hace que cada turno sucesivo dependa secuencialmente del turno previo.

Una regla de distribución para las primeras emisiones es la que gobierna la fórmula básica: la persona que contesta habla primero. Otra regla de la apertura de conversación consiste en que quien llama provee el primer tópico de la conversación. Para Schegloff, la regla de distribución no sólo parece seguirse rutinariamente en la práctica real de los que hablan por teléfono, sino que también establece un formato por el cual se mantiene un control en el desarrollo de la actividad.

Debe tenerse en cuenta que una convocatoria es la primera parte de una secuencia de dos secciones. Existen varios elementos que pueden ser usados como convocatoria, por lo que hay también varios elementos que se usan como respuesta. Para el español tenemos aló, hola, sí, diga, etc. Algunas secuencias típicas de convocatoria-respuesta son el sonido del teléfonoaló, ¿Miguel?-¿sí?, disculpe-¿sí?, etc.

En la interacción del teléfono, el solo levantamiento del auricular sirve para establecer la presencia de una persona al otro lado de la línea. Sin embargo, esto no establece la disponibilidad para seguir la conversación. Como dice Schegloff, hoy en día es posible oír en el número al que uno está llamando la respuesta de una voz humana; sin embargo, no contesta un ser humano. A pesar de lo anterior, generalmente las máquinas como la contestadora automática están basadas en principios sociales y no mecánicos. La voz grabada de la máquina no solo responde al timbre del teléfono, sino que también da información acerca de cuándo estará disponible la persona llamada para recibir el mensaje. Por consiguiente, tanto la estructura $a b a b$ como las propiedades de la secuencia convocatoria-respuesta se conservan.

No obstante, debemos decir que la situación comunicativa en la que se deja un mensaje en la contestadora no corresponde a la situación prototípica de la comunicación oral. En primer lugar, no hay posibilidad de negociación temática ni de los turnos de habla: el que llama debe esperar la indicación mecánica para grabar su mensaje, sin posibilidades de interactuar con un interlocutor; es decir, después de la indicación de la máquina, su emisión se construye como un monólogo, sin transiciones de turno de habla y sin indicadores de comprensión del mensaje (de aquí, precisamente, los problemas que se producen cuando se escuchan posteriormente los mensajes y no se comprende parte de ellos), con una duración corta establecida por la máquina y con la consecuente incertidumbre acerca de la forma en la que la persona a quien va dirigido el mensaje lo interpretará in absentia del que llamó.

Este carácter específico de la "interacción" con la contestadora explica por qué las personas poco acostumbradas a este tipo de situación se sienten desconcertadas ante ellas y no saben cómo comportarse lingüísticamente. En el siguiente ejemplo, una mujer ve frustrado su intento de establecer una comunicación directa con su hijo y, ante su poco contacto con las máquinas contestadoras, le pide ayuda a una nieta. A pesar de las indicaciones de esta, la 
mujer no logra acomodarse a la inesperada situación comunicativa que se le propone; deja el mensaje con gran dubitación y cuelga el auricular sin salir de su desconcierto:

Nieta: Aló tío / suave un momento

Mujer: Alóó / aló

Nieta: No / abuelita /ah no / es que es / es la contestadora

Mujer: Idiay / ¿qué digo?

Nieta: Diga diga / el recado

Mujer: Llámeme al / llame / llame a su mamá /// Diay pero / [cuelga]

Aún así, los mensajes dejados en la contestadora siguen remitiendo a los hablantes a los esquemas de conversaciones cotidianos, razón por la cual gran parte del comportamiento verbal de estos es básicamente el mismo a la hora de conversar cara a cara, por medio del teléfono o en la grabación de un mensaje en la máquina. Es por ello que, normalmente, la máquina se toma como el interlocutor que se esperaba y las formas verbales empleadas se codifican en segunda persona singular, esto es, la persona del interlocutor en su papel de oyente; además, se le hacen preguntas directas e, incluso, se establece una discusión, como ocurre en el siguiente ejemplo:

\begin{abstract}
Gracias a Dios tenés esta maquinita que aquí puedo dejarte los mensajes / ya que sos tan cobarde / de no llamar III porque es lo que sos / decís que te llame / y / como ponés la maquinita ahí te escudás en ella III pero / no creás / yo lo único que quiero es hablar con usted // porque Teresa ahí anda haciendo loco y dice que nos va a encarar / no sé qué es que quiere desenmascarar ella / [...] yo quería hablar con usted primeramente pero si usted así no lo quiere / entonces / si usted cree que yo el domingo hice un alboroto / el que se va a armar después no va a ser nada / comparado // a lo que yo voy a hablar después / eso es lo que usted quiere.
\end{abstract}

\title{
3. El mensaje en la contestadora como marco discursivo
}

Es interesante notar que, para dejar un mensaje en la máquina contestadora, los hablantes siguen una estructura más o menos invariable. Primero, hay que recordar que se trata de una secuencia de convocatoria-respuesta, en la cual la primera parte está representada por el sonido del timbre del teléfono y la segunda, por el mensaje grabado como respuesta a esa convocatoria.

Normalmente, los seres humanos acomodamos nuestras acciones y comportamientos, sean verbales o de otra índole, a las expectativas que nos formamos acerca de las situaciones en las que nos vemos inmersos. Estas expectativas se basan en las experiencias previas y en las relaciones que establecemos entre determinadas prácticas culturales de las que hemos oído o que hemos visto o vivido y nuevas situaciones no muy distintas a las anteriores. El conocimiento sobre el mundo se organiza con base en estas estructuras de expectativas culturales y se usa para predecir cómo actuar en las situaciones futuras. De esta forma, la mente parece trabajar por medio de situaciones y comportamientos prototípicos, a partir de los cuales se crean expectativas, se identifican los eventos particulares y se interpretan. A pesar de la diversidad de nomenclaturas y aproximaciones teóricas al problema, este conjunto de expectativas se suele llamar "marco" (Tannen 1993). 
En la situación de tener que dejar un mensaje en una máquina contestadora, los hablantes recurren a un esquema básico preestablecido. El conocimiento de este esquema o marco incluye información estereotipada, en el sentido de que la mayoría de los mensajes de recibimiento en las contestadoras tienen el mismo formato, tal como se observa en el mensaje estándar en la introducción de este artículo y en los siguientes ejemplos de una máquina en una casa de habitación y de un teléfono celular, respectivamente:

Está llamando al XXXX // en este momento no podemos atenderle / si deja su nombre / número de teléfono y mensaje / le devolveremos la llamada tan pronto nos sea posible.

Usted está llamando al celular de Rogelio Arguedas / por favor deje su mensaje después del tono / gracias.

Los mensajes de recibimiento pregrabados pueden variar en su forma, pero, por lo general, el mensaje-respuesta de la máquina recibe a quien llama con un saludo, seguido por la indicación del número o el nombre del propietario de la casa. Continúa luego con una pequeña justificación del porqué el que atiende el teléfono no es una persona, sino la contestadora automática, y por último, pero quizá lo más importante, establece los parámetros estructurales del mensaje que $a$ debe dejar.

Por lo general, los hablantes van a incluir u omitir información dependiendo de factores tales como el grado de formalidad, el tipo de relación que se mantenga con la persona llamada, el acto de habla que se pretende llevar a cabo, etc.; empero, parece desprenderse del análisis de los mensajes de nuestro corpus que el orden de la información y ciertos aspectos de la forma en como se codifica están regidos por el marco en cuestión. Así, algunos de las personas que llamaron se encontraron con el siguiente mensaje-respuesta de la máquina:

Hola / está llamando al XXXX / casa de Juan Fernández / en este momento no podemos atenderlo / por favor después del tono deje su mensaje nombre y número de teléfono / gracias.

A pesar de que la estructura propuesta es mensaje, nombre y número de teléfono en este orden, ninguno de los hablantes siguió esta forma. Lo anterior y el hecho de que entre sí los mensajes concuerdan en términos generales en cuanto a la estructura, induce a pensar que el tipo de discurso representado por los mensajes en una contestadora tiene una secuencialidad propia y ritualizada, que hace caso omiso de otro orden propuesto que atente contra la lógica interna de la jerarquización de la información incluida en el mensaje.

Muchos de los mensajes empiezan con los siguientes dos elementos: el nombre de la persona a quien se le deja el mensaje y el nombre del que lo deja. Los ejemplos 1-3 fueron dejados en una máquina de una casa de habitación; el 4, en un teléfono celular:

1. Juan / es Carol de la Academia.

2. Juan / habla Margarita.

3. Miguel / soy yo / Sonia

4. Emilio / es Laura

Sin embargo, es necesario hacer notar que el segundo elemento está sujeto al conocimiento que A sabe que B tiene sobre A; es decir, si lo conoce personalmente o si su relación 
es íntima, o, por el contrario, si A sabe que B podría no recordarlo y por eso tiene que presentarse por medio de la indicación de su relación con otra persona de más familiaridad para B:

\author{
5. Juan / soy el novio de Margarita \\ 6. Yo soy la hermana de Alonso Calvo \\ 7. $\quad$ Miguel / le habla Marta / la esposa de Esteban / su tio \\ 8. Don Pedro / le habla Carol de Viajes Calón / del Departamento de Cobro Administrativo
}

Algunos de los mensajes incluyen un saludo, especialmente cuando se trata de una persona que no conoce en absoluto al que está llamando:

9. Buenas tardes / yo soy la hermana de Alonso Calvo

10. Buenos días don Miguel Rojas / mi nombre es Auxiliadora Márquez / de Noticias Repretel

Otros mensajes presentan la particularidad de empezar con un 'aló', lo cual no deja de ser una muestra de cierta extrañeza en A al encontrarse con otro tipo de discurso al que esperaba, es decir, no con una comunicación directa con $\mathrm{B}$ :

11. Aló / Juan / Soy yo / Alex

12. [conversa con otra persona y no se da cuenta de que contestó la máquina] Aló / es para dejarle el recado a...

Después de estos elementos se coloca el mensaje propiamente dicho, el número de teléfono si es necesario y casi siempre un agradecimiento corto o una despedida. Algunos de los mensajes incluyen como agradecimiento "gracias" y otros, las fórmulas de despedida "chao" y "adiós":

\title{
13. Juan / es Leticia [...] gracias
}

Como sería de esperar, el número de teléfono solicitado en el mensaje "contestador" solamente se consigna cuando se sabe que la persona a la que va dirigido el mensaje no lo conoce. Además, este dato depende de la solicitud que haga A. siguiente:

En resumen, la estructura general que se puede inducir de los datos analizados es la

a. Saludo: es un elemento facultativo y poco frecuente.

b. Nombre de la persona a quien está dirigido el mensaje: elemento obligatorio, incluso en los mensajes dejados en el teléfono celular.

c. Nombre de la persona que habla: elemento obligatorio.

d. Cuerpo del mensaje: dependiendo del acto de habla que se lleve a cabo, necesita recurrir a ciertas estrategias de cortesía. También, por lo general, incluye una justificación ya sea para haber dejado el mensaje o para llevar a cabo el acto de habla específico.

e. Número de teléfono de A: elemento facultativo que depende de la petición hecha. 
f. Agradecimiento: elemento facultativo.

g. Despedida: elemento facultativo.

Los ejemplos 14-16 muestran las posibles combinaciones de secuencias:

14. b-Juan, c-es Leticia. d-No se le olvide llevarme lo de Español eh / porfa, f-gracias

15. Aló / b-Juan. c-Soy yo / Alex...d-Mae / necesito hablar con usted para un negocio ahí de unas clases de español / para que usted me ayude e-Llámeme al XXXX / para hacer un arreglo con usted. f-Gracias

16. a-Buenos días b-don Miguel Rojas / c-mi nombre es Auxiliadora Márquez / de Noticias Repretel / d-eh / estoy interesada en conversar con usted sobre / eh / un tema / dee / la enseñanza bilingüe / este / e-por favor si puede devolverme la llamada al XXXX / eh / la persona que me hizo el contacto fue la profesora de enseñanza especial de la XX / eh / le agradezco mucho me devuelva la llamada

El ejemplo 16 muestra cómo también se pueden incluir otros elementos no contemplados en el esquema anterior. En este caso, se trata de información adicional que explicaría el porqué la persona que llama tuvo acceso a un número de teléfono privado.

Como se dijo en la introducción, los mensajes fueron dejados en una casa de habitación y en un teléfono celular, por lo que esta estructura podría variar muchísimo en relación con los mensajes más formales dejados en una oficina. Ciertamente, se trata de una secuencia de convocatoria-respuesta, con un formato muy similar al de las aperturas de conversación telefónicas estudiadas por Schegloff (1986), pero con la diferencia de que B no participa más de una vez y A debe acomodarse a las exigencias de otro discurso diferente al que se había propuesto recurrir cuando realizó la llamada.

\section{Estrategias de cortesía y mensajes en la contestadora}

Las observaciones que hasta el momento hemos realizado nos dan solamente una pista sobre la estructura de los mensajes dejados en la máquina contestadora. Un asunto al que es necesario referirse al tratar de analizar los mensajes es la forma en la cual el que llama debe manejar el discurso "cortésmente" para alcanzar sus propósitos. Robin Lakoff (Bonvillain 1993) propone dos reglas de la competencia pragmática:

1. Sea claro.

2. Sea cortés.

Idealmente, los hablantes tratan de cumplir con estos dos requisitos, pero en casos de conflicto la cortesía se sobrepone: "it is considered more important in a conversation to avoid offense than to achieve clarity... since in most informal conversations, actual communication of important ideas is secondary to reaffirming and strengthening relationships" (Bonvillain 1993: 131). 
Los postulados sobre la cortesía de Lakoff son:

1. No se imponga.

2. Dé opciones.

3. Haga que A se sienta bien, sea amigable.

La regla dos implica el uso de expresiones mitigadas que le permitan al oyente formarse y tomar sus propias decisiones.

En la misma línea de las investigaciones sobre la cortesía, Penelope Brown y Stephen Levinson (1987) postulan algunos universales de cooperación en la conducta cortés, los cuales responden a la necesidad del grupo social de minimizar los conflictos entre sus miembros. Para ellos, la cortesía se refiere a la imagen, definida esta como "el amor propio" del individuo o la imagen pública que cada persona quiere mostrar. Hay dos tipos básicos de imagen: la positiva y la negativa. La positiva se refiere a querer ser aprobado; la negativa, a tener control de las acciones. De acuerdo con esta diferenciación, se distinguen las siguientes estrategias de conducta cortés:

1. Cortesía positiva: orientada a la imagen positiva del oyente. El hablante reconoce el deseo del oyente de que su imagen positiva sea respetada. Las estrategias de cortesía positiva expresan solidaridad, amistad y reciprocidad.

2. Cortesía negativa: orientada al deseo del oyente de que no se le impongan; el hablante reconoce los derechos de autonomía del oyente.

3. Estrategias indirectas que evitan hacer explícita o inequívoca la imposición en el oyente.

Los actos exhortativos son los actos de habla que, por excelencia, amenazan el derecho del individuo para actuar autónomamente; son los que quizá mayormente atentan contra la imagen negativa del oyente. Es por esto que, mediante un procedimiento racional, el hablante selecciona una estrategia y esta racionalidad se manifiesta en dos formas:

1) Por medio de la justificación del acto de habla.

2) Por medio de la valoración del balance coste-beneficio.

La segunda se refiere a la realización del acto de habla con la estrategia de cortesía que logre mejor el objetivo y con un coste verbal menor. La primera corresponde a:

aclaraciones hechas para motivar qué es lo que induce al locutor a realizar el acto de habla. Este tipo de comportamiento racional se refleja particularmente en la realización de los actos exhortativos (...), [pues] constituyen la clase de actos de habla que amenazan el espacio intencional del interlocutor, razón por la cual en no pocas ocasiones el hablante se ve obligado a motivarlas. La justificación exhortativa, por tanto, es un acto de cortesía que sirve para indicar al oyente que su libertad de acción no se ve impedida arbitraria o inútilmente (Haverkate 1994: 36).

Por supuesto, la teoría de Brown y Levinson (1987) es mucho más amplia y compleja de lo que se ha señalado aquí. Se han reseñado solamente los aspectos más relevantes para el análisis del corpus seleccionado. 
Como se dijo en la sección 3 de este artículo, el grueso del mensaje es lo que llamamos "cuerpo". En esta parte, A necesita condensar muy brevemente lo que pensaba decir o pedir valiéndose de estrategias muy diversas, incluyendo el cambio de una estrategia por otra dependiendo de la forma en que reacciona B. La conversación telefónica presenta de todas formas la peculiaridad de que tanto A como B tienen que limitarse a recursos lingüísticos o sonoros para interactuar, pues no tienen a su disposición ninguno de los recursos cinésicos o proxémicos de los que normalmente podrían echar mano. Ahora bien, al menos en una conversación telefónica en la que ambos participantes interactúan, existe siempre la posibilidad de cambiar, rectificar, aminorar o explicar (incluso tergiversar) lo que se dice en el transcurso del desarrollo de la conversación; pero en el tipo de discurso del que nos estamos ocupando, A sabe que no puede cambiar lo que dice por muchas razones: primero, el mensaje queda grabado, por lo que no puede negarse nada de lo que B oyó; segundo, A tiene que ser muy breve y esto le impide justificarse ampliamente; tercero, A desconoce por completo la reacción de B al escuchar el mensaje, por lo que se ve impedido de jugar con otros recursos y acomodarlos o desecharlos según sus intereses. Lo anterior constituye quizá una de las mayores diferencias con otras prácticas discursivas, pues aún las cartas e informes escritos son muy bien planeados y el escritor puede rectificar cualquier idea antes de ponerla en el papel.

En el transcurso de una conversación telefónica, A y B "juegan” mutuamente y manejan el discurso según sus conveniencias, como se muestra en el siguiente fragmento:

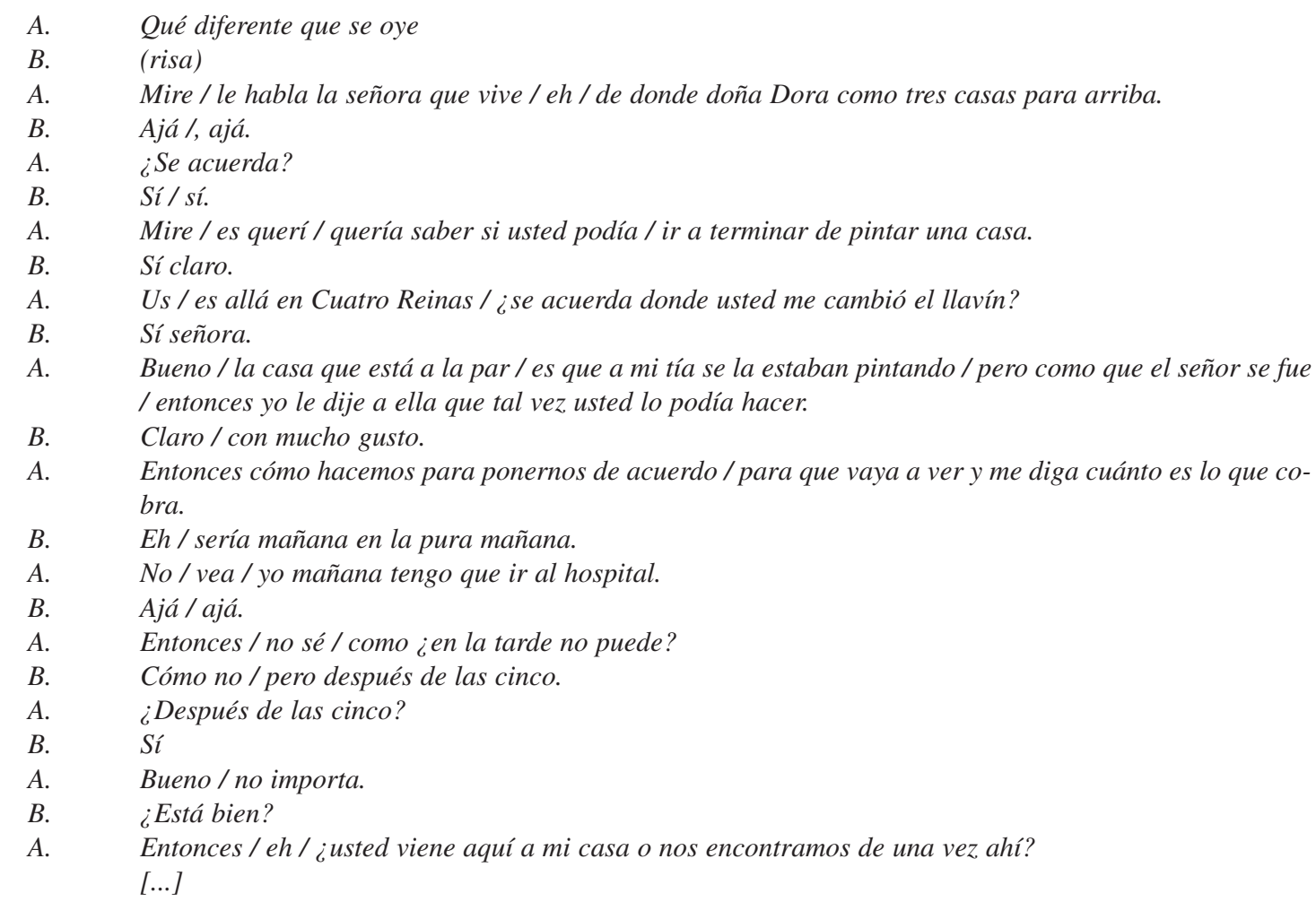


A tiene la oportunidad de dar más indicaciones y de hacer su petición con rodeos, puede cerciorarse de que B la conoce y que la recuerda. B puede dar a conocer su opinión y llegar a un acuerdo mutuo con A; por ejemplo, la hora y el lugar en que se van a encontrar.

Todo lo anterior no tiene cabida en un mensaje dejado en una máquina contestadora y, por eso, A tiene tres opciones: dejar el mensaje y hacer la petición esperando haber acertado en la estrategia de cortesía que eligió, ser completamente vago en la petición y postergarla para el momento en que pueda hablar directamente con B, o bien colgar el teléfono. La elección de cualquiera de ellas está sujeta a la urgencia de lo que se desea comunicar, la confianza que A le tiene a B, y la relevancia de lo que se desea pedir. Por eso, no es nada infrecuente que A opte por colgar el teléfono y llamar luego con la esperanza de poder acceder a una conversación directa con $\mathrm{B}$, pero muchas veces A necesita hacer una petición que debe ser rechazada o aceptada por $\mathrm{B}$ en un plazo muy corto. Por ejemplo, véase el siguiente mensaje dejado por la jefa de B, quien evidentemente necesita una respuesta lo más pronto posible de su subalterno:

\footnotetext{
Juan / es Carol de la Academia / es que /. tu estudiante Estefani quería empezar mañana a las ocho / porque ellas van para un tour al Arenal / llamame a la casa por favor para confirmar a ver si vos podés /. llamame al XXX / gracias.
}

En el mensaje anterior, A necesita ser muy cuidadosa con su petición, pues esta implica ejercer su poder sobre su empleado, quien no está obligado a acceder, pero quien tampoco puede negarse fácilmente sin preocuparse por dañar sus relaciones con su jefa. Es obvio que estamos aquí ante un caso de cortesía negativa, pues lo que está en juego es la imagen negativa de B, su deseo de que no le impongan algo que él no desea hacer. Es un acto exhortativo, por ello amenaza el derecho de B de actuar autónomamente. En el mensaje en cuestión, A inteligentemente recurre a los postulados de la cortesía de Lakoff:

1. No se impone, deja claro que la estudiante desea empezar la clase antes de la hora establecida, pero no dice que tiene que ser obligatoriamente así; lingüísticamente, esto lo expresa, por ejemplo, con el verbo 'querer' en imperfecto, lo cual le da un aire de menos obligatoriedad a la petición que si lo hiciera en presente.

2. Da opciones, expresa su deseo de saber si B tiene la posibilidad de acceder a su petición o si, por el contrario, algo se lo impide. Verbalmente, esto lo expresa al decir: "para confirmar a ver si vos podés".

3. Es amigable, intenta establecer una relación de cercanía y familiaridad con B, posiblemente esto hace que el hecho de que A le vosee a B no parezca extraño en este contexto.

A selecciona una estrategia para lograr sus fines: dado que no desea imponerse, recurre a justificar su emisión de un acto exhortativo: "Es que /.tu estudiante Estefani quería empezar mañana a las ocho / porque ellas van para un tour al Arenal.

Puede notarse que la fórmula "es que" (dicho en este caso con un alargamiento muy fuerte de la última vocal y con una gran pausa después) es un elemento muy claro para introducir una justificación. De hecho, también en una conversación directa los hablantes recurren a él para marcar el inicio de una explicación de por qué llevan a cabo la petición, como en el 
ejemplo de la conversación telefónica antes comentada: “A. Bueno / la casa que está a la par / es que a mi tía se la estaban pintando / pero como que el señor se fue / entonces yo le dije..." Véase cómo se emplea, asimismo, en el siguiente mensaje:

Juan / yo soy el novio de Margarita / es que ella tenía que entregarle un libro a usted y me lo dio a mí pa-
ra que se lo fuera a dejar / pero a mí en el trabajo no me dieron permiso / entonces yo llamé a Margarita
para decirle / entonces ella dice que no importa / que ella se lo deja el miércoles / gracias.

En todo caso, sea que recurra a la fórmula "es que" o no, A normalmente empleará formas lingüísticas mitigadoras de la imposición (las señalamos con negrita en la transcripción):

Don Pedro / le habla Carol de Viajes Colón / del Departamento de Cobro Administrativo / yo lo llamo nada más para decirle quee /eh / nada más le quedan cinco cuotas de atraso por cinco mil quinientos colones para ponerse al día / entonces eh / como es poquito yo lo llamo a usted para ver siii / usted podría confirmarnos y ponerse al día para mandarle de nuevo al cobrador / cualquier cosa me puede llamar al $\mathrm{XXXX} /$ gracias.

Claro que la estrategia de cortesía elegida depende en gran medida, como dijimos, de la situación concreta. El siguiente mensaje es directo y no se detiene en ninguna justificación de la petición, pues A ya había hablado con B y éste había aceptado su solicitud:

Juan / es Leticia / no se le olvide llevarme lo de Española/ eh / porfa / gracias.

Pero después de formular un mensaje tan directo, A titubea por un momento (eso se muestra en eh) y decide agregar un 'porfa' para mitigar la petición y no atentar contra la imagen negativa de $\mathrm{B}$.

A también tiene la opción de ser muy vago en su mensaje y así no comprometerse ni comprometer a B, quien, según la forma en que A le pida algo tal vez muy importante, puede indisponerse y preparar una negativa ad hoc. Esto se revela en el siguiente mensaje, en el cual A se vale de muchos recursos para ser poco preciso y nada comprometedor, por ejemplo: "necesito hablar con usted para un negocio ahî":

Aló / Juan / soy yo / Alex / mae / necesito hablar con usted para un negocio ahí de unas clases de español / para que usted me ayude / llámeme al XXXX .para hacer un arreglo con usted / gracias.

También existe la posibilidad de que A no tenga ningún reparo en dejar explícito su poder sobre B y, por lo tanto, que no recurra a mitigar cortésmente su emisión; o bien, que la relación entre A y B permita el laconismo y la falta de justificación:

Esteban / llámeme / necesito hablar con usted // gracias.

Desde luego, en los mensajes telefónicos, la fuerza ilocutiva del acto de habla puede ser distinta a la de una petición. Entre otros actos, también A podría querer disculparse, felicitar a B, hacer un reclamo o una amenaza (como el ejemplo final de la sección 2), entre otras muchas posibilidades, para las cuales podrían ser irrelevantes las estrategias de cortesía. Sirvan los siguientes ejemplos simplemente para ilustrar lo dicho: 
Intención: disculparse

Miguel / es Laura / ¿cómo vas? / mirá llego / estoy un poco atrasada // entonces voy a pasar pero despuesito de las cinco / entonces después te llamo para ver si pudiste leer el trabajo / chao

Intención: felicitar

Aló / Miguel / es Joaquín Fernández / ¿cómo te va? / mirá te llamaba paraa felicitarte por / un añito más I a tu casa / y yo no sé / como nunca estás por ahí / y entonces me conseguí tu celular / entonces que la hayás pasado muy bien ayer / yy / no sé / después nos hablamos un día de estos / oquey / bueno adiós

Intención: informar

Lucrecia / es Ana / ya encontré los programas / no tiene que llamarme / gracias

Intención: invitar

Miguel / le habla Marta / la esposa de Luis / su tío / Miguel hágame un favor / llámeme / cuando apenas llegue usted / yo estoy aquí en la casa / es para / para invitarlo el domingo que le vamos a hacer algo para el día del padre / a su papá / entonces va a ser en Heredia / entonces yo quería hablar con usted / para ver si usted no se comprometía con ningún lado para que fuera allá // bueno / ojalá que pueda / me llama porfa / gracias

\section{Conclusión}

Aunque el corpus y el análisis tratados aquí son muy breves, se puede decir que el discurso de los mensajes telefónicos dejados en la máquina contestadora constituye un marco con su propia especificidad estructural y, asimismo, comparte muchas características con el discurso conversacional. No obstante, las personas que llaman se ven en el dilema inesperado de tener que elegir entre dejar un mensaje y arriesgarse a utilizar una estrategia de cortesía fija valiéndose de mecanismos puramente lingüísticos, ser impreciso y esperar una situación más controlable, o simplemente poner el auricular de nuevo en el lugar de donde lo tomó sin decir nada, como ocurre no pocas veces.

\section{Notas}

1. Para la transcripción de los mensajes se siguieron las siguientes convenciones:

Los alargamientos fonéticos se indican por medio de la repetición del elemento alargado.

Las pausas se marcan según su duración relativa: / (pausa muy breve), // (pausa de duración media) y /// (pausa larga). Valga aclarar que esta transcripción es aproximada y no se realizó mediante ningún instrumento especializado.

Los puntos suspensivos entre corchetes indican porciones discursivas omitidas.

2. Los pares adyacentes consisten en secuencias con las siguientes características: dos emisiones de cierta duración, posición adyacente de las emisiones que los componen, y hablantes diferentes que produzcan cada emisión. La segunda emisión (la segunda parte del par) debe mostrar una secuencia en relación con la primera emisión de la secuencia a la que pertenece por una tipología cultural preestablecida (por ejemplo, pregunta-respuesta, ofrecimiento-aceptación). La regla básica de operación de un par adyacente es la siguiente: dada la producción reconocible de una primera parte del par y su conclusión respectiva, el hablante deberá detenerse y un nuevo hablante deberá comenzar y producir una segunda parte del par del tipo de par correspondiente del que la primera parte es reconociblemente un miembro. (Schegloff 1978). 


\section{Bibliografía}

Calsamiglia Blancafort, Helena y Amparo Tusón Valls. 1999. Las cosas del decir. Manual de análisis del discurso. Barcelona: Ariel.

Brown, Penelope y Stephen C. Levinson. 1987. Politeness: Some Universals in Language Usage. Cambridge: Cambridge University Press.

Dressler, Wolfgang U. (ed.). 1978. Current trends in textlinguistics. Berlin: Walter de Gruyter.

Gumperz, John y Dell Hymes (eds). 1986. Directions in Sociolinguistics. Oxford: Basil Blackwell.

Haverkate, Henk, 1994. La cortesía verbal. Madrid: Gredos.

Nancy, Bonvillain, 1993. Language, Culture and Communication. New Jersey: Prentice-Hall.

Schegloff, Emanuel. 1986. "Sequencing in Conversational Openings”. En: Gumperz, John y Dell Hymes (eds).

1978. “On some questions and ambiguities in conversation”. En: Dressler, W. (ed.)

Tannen, Deborah. 1993. "What's in a Frame? Surface Evidence for Underlying Expectations”. En: Tannen, D. (ed.): 15-56.

Tannen, Deborah (ed.). 1993. Framing in discourse. Oxford: Oxford University Press 